\title{
UN OLVIDADO CRONISTA: FRAY REGINALDO DE LIZÁRRAGA (CA. 1539-1609)
}

En las involuntarias pausas de su vida de viajero, este fraile viandante compuso una media docena de libros que enumeró su primer biógrafo, fray Juan Meléndez ${ }^{1}$ : los Cinco libros del Pentateuco, en tres volúmenes; una colección de Lugares comunes de la Sagrada Escritura, donde se concuerdan textos que no parecía fácil armonizar; otra colección de Sermones de tiempo y santos; un Comento de los emblemas de Alciato; y finalmente, un libro sobre la Descripción y población de las Indias, el único que ha sobrevivido, después de reaparecer casualmente en el siglo xvir. Por otra parte, también se ha perdido la biografía de fray Jerónimo de Loayza, primer arzobispo de Lima.

El libro de la Descripción y población de las Indias ha llegado a nosotros con otro título: Descripción breve de toda la tierra del Perú, Tucumán, Rio de la Plata y Chile. Su autor la dedicó al Conde de Lemos, que era entonces presidente del Consejo de Indias. E1 manuscrito se perdió quizá cuando se envió a España para publicarse, desventura común a muchos libros de indianos. El cronista de la orden dominicana del Perú, fray Juan Meléndez, lo encontró en Madrid en poder del obispo de Filipinas, fray Juan Durán, y transcribió largos pasajes en sus Tesoros verdaderos de las Indias ${ }^{2}$. Esa

- Son incompletos o erróncos todos los estudios biográficos y bibliográficos de Lizárraga y su obra: CRescente Errázuriz, Los origenes de la Iglesia chilena, $154^{0-1603}$, Santiago de Chile, 1873 , que completó y amplió las referencias más antiguas de Eyzagulrre, Histoire du Chili, 3 vols., Paris-Lille, 1855; José Toribio Medrna, Historia de la literatura colonial, Santiago de Chile, 1882 , y Diccionario biográfico colonial de Chile, Santiago de Chile, 19o6. La fuente principal de estos estudios es la noticia que sobre nuestro dominico dió fray JuAN MrLíndez en sus Tesoros verdaderos de las Indias, Madrid, 1681-1682? En la Historia de la literatura argentina que dirige Rafael Alberto Arrieta, en prensa actualmente, publicamos una biografía detenida de Lizárraga.

${ }^{2}$ Meléndez, op. cit., Introducción, y lib. V, cap. xiv, pág. 597. Ese manuscrito, depositado hoy en la biblioteca de la Universidad de Zaragoza, es el que reprodujo Manuel Serrano y Sanz en la NBAE, vol. XV, Madrid, 19og, págs. $485-660$. (A esta edición remitirán nuestras citas). Sobre ella se hizo la edición del doctor Ricardo Rojas, que tituló la obra Descripción colonial (Buenos Aires, 1916). Véase el estudio del manuscrito de Zaragoza en la Advertencia de Serrano y Sanz al vol. XIII de la NBAE. Andrés González de Barcia pensaba publicar la 
referencia salvó del olvido el libro de Lizárraga, llamando la atención de la crítica hacia ella, y hay que agraclecérselo, porque nos ha rescatado un libro diverso de sus semejantes, vivaz y fidedigno, descriptivo e histórico, tan agradable y leve en la descripción como en el relato. En una oportunidad el autor lo llama "compendio"; en otra, dice que "es más recopilación de historia que historia", y en ambos casos apunta la concisión, que es su cualidad característica. Es, al mismo tiempo, historia natural y moral de las regiones donde vivió Lizárraga y de las rutas numerosas que siguió en el cumplimiento de su misión. El propósito del autor fué escribir un libro de sus viajes; por eso se trata rápidamente la historia política, que parece añadidura tardía. Es verosímil conjeturar que se le ocurriera insertar la parte histórica para tener oportunidad de expresar su gratitud a los dos virreyes del Perú, Marqués de Cañete (1556-1561) y García Hurtado de Mendoza, hijo del anterior (1590-1596), a quienes elogia largamente. Hacia los mismos años, nuestro dominico fray Reginaldo de Lizárraga, y Pedro de Oña, estudiante de la Universidad de San Marcos de Lima, agradecían mercedes pasadas y futuras de ambos virreyes, dedicando al segundo Marqués de Cañete un poema entero el uno (Arauco domado, Lima, 1596), y capítulos muy detenidos de su historia el otro (Descripción, libro II, capítulos XI.IX-LX, y además, capítulos viII-XXıI, elogio del primer Marqués de Cañete). Ese agradecimiento no altera apreciablemente la imparcialidad de fray Reginaldo que, en el temor de que le juzguen apasionado, prefiere callarse a opinar desfavorablemente.

Lizárraga no se propone hacer un relato novelesco de viajes por comarcas extrañas, como el de Álvar Núñez por ejemplo, sino poco más que una guía destinada a fines prácticos, como un itinerario para peregrinos y misioneros, pero sin exageraciones ni milagrerías. Así, por ejemplo, de la Descripción podemos entresacar una especie de refranero de caminantes, donde se elogian las cualidades de cada lugar: En Cañete, come pan y vete; En Ica, hinche la bota y pica; De hombres y caballos de Tucumán no hay que fiar; la ciudad de La Plata (es decir, Charcas o Chuquisaca) excede a todas las del Perú en templo, temple, fuente y puente, etcétera ${ }^{3}$. No es refrán de

D)scripción, y en 1735 hizo sacar una copia que se cncuentra en la B. N. M. y fuć la que imprimió Carlos Alberto Romero en la Revista Histórica de Iima, II, 1907, págs. 261-283 y 459-543, con una excelente introducción suya (se publicó al año siguiente en volumen aparte: Descripción y población de las Indias por fray Reginaldo de Lizárraga, Lima, 1908). La copia de Madrid lleva cl siguiente título del copista: Libro que el reverendisimo fray Baltasar de Ovando [ése fué el nombre y apellido de Lizárraga antes de entrar en religión] compuso siendo obispo de la ciudad Imperial, del Reyno de Chile, Relixioso del convento de Santo Domingo, año de I605: es muy defectuosa y abrevia el original.

"Descripción, libro I, capítulos LviII (pág. 519a), LXI (pág. 521b) y cxvi (pág. 549b); lib. II, cap. Lxv (pág. 638b). 
viajero sino altiva expresión de "pretendiente" que no pide sino exige compensación: Chincha o Nasca o nada .

De su mucho andar se le han quedado a Lizárraga, además de refranes, palabras de la lengua marinera que salpican su vocabulario (demorar, box 'boj', morro, garúa, bernia ${ }^{5}$ ) y un conocimiento exacto de la maniobra, que revela especialmente en su crítica minuciosa a las disposiciones que se tomaron para una batalla con los corsarios. ¿No le parece gravísimo defecto en la educación de los criollos de Lima no tener gusto ni afición por el mar? ${ }^{6}$

No hay rastros de composición, ni excesivo aliño literario. Reminiscencias de libros, pocas pero muy curiosas: tres veces se recuerdan diálogos platónicos ${ }^{7}$, y otra, un Teatro del mundos; además, en una oportunidad y sin nombrarla, cruza un vago recuerdo de la Celestina $^{9}$. Pero en este libro sin literatura hay páginas que son ejemplos de la prosa más llana y más semejante al hablar de entonces. Véase por ejemplo este párrafo en que el cronista habla de los mestizos del Perú:

Castigaron los viejos conquistadores y criaron en mucha policía a los montañeses y a los meros españoles, como a ellos los. criaron sus padres. Ningún muchacho había de hablar ni cubrir cabeza ni sentarse delante de los viejos aunque tuviese(n) barbas; ni los viejos al más estirado llamaban sino $t u$, cuando mucho un vos muy largo. A los montañeses enseñaban primero a leer, escribir y contar; luego les daban oficio, y a lo que más se inclinaban es a herreros, y son primísimos oficiales; son grandes arcabuceros, flecheros y nadadores, recios hombres a caballo; andando en la guerra, luego quitan las calzas y zapatos y desnudan los brazos; ya han perdido esta policía, muertos los viejos, y son

${ }^{2}$ Descripción, I, IXIII (pág. $\left.5^{2} 1 b\right)$.

s Descripción, I, Lvi (pág. $5^{1} 7^{a}$ ): "Dos leguas desta ciudad [Lima], a la parte del poniente, demora (hablemos como marineros) el puerto desta ciudad, llamado el Callao" (y cf. I, Lxx, pág. 527b); I, Lxvil (pág. $523^{b}$ ): "La playa de Arica es muy grande y muy conocida por un morro (así lo llaman los marineros)..." (cf. también págs. $524 a$ y $5^{2} 5 b$ ); I, xıI (pág. 492a): "desde mayo comienzan unas garúas, llamadas así de los marineros, que duran hasta otubre" (cf. también pág. $492 b$, y I, Lxıı, pág. $522 a)$. Etc., etc.

'Descripción, II, LII-LIII (págs. 624b-626b), y I, LV (pág. $517 a)$.

7 Timeo: I, I (pág. 485a); Leyes: I, LV (pág. 517a); República: I, I (pág. 517a).

${ }^{8}$ Descripción, I, cxvi (pág. 568a): “y porque no quiero cansar al prudente lector, le ruego lea el segundo libro del Teatro del mundo, donde verá los inconvenientes irremediables que de las malas costumbres de las amas han subcedido".

* Descripción, II, Lvir: "es cosa de lístima haya ningunos religiosos en ella, porque un solo fraile en un convento y en un solo pucblo ¿qué ha de hacer? Un ánima sola, decimos, ni canta ni llora, y más en tiempos tan miserables donde las cosas van tan de caída”. En la Celestina, auto VII, también aparecen asociados ambos refranes: "Un ánima sola ni canta ni llora; un solo acto no hace hábito; un fraile solo pocas veces lo encontrarás por la calle". 
la gente más mentirosa del mundo; y como un hombre no tracte verdad, no le pidan honra ${ }^{10}$.

La primera parte, con la descripción del Perú a lo largo de los dos caminos, el de la costa (desde Puerto Viejo hasta Copiapó, capítulos III-LXVIII) y el de la Sierra (desde Quito hasta Talina, capítulos LXIX-CX), y la segunda parte, con la nómina de los prelados (capítulos I-VI), gobernadores y virreyes desde el licenciado Vaca de Castro hasta el segundo Marqués de Cañete (capítulos vir-LXI) formaban, probablemente, la primera redacción de la obra, que se compuso antes del último viaje a Chile, hacia mediados de $1602^{11}$. Aunque ya conocía Tucumán y Chile, había dejado ambas gobernaciones fuera de su plan, quizá porque no le atraían demasiado a él, que vivía con los ojos puestos en Lima; pero cuando se puso a añadir la obra decidió incluirlas, alterando gravemente su pensamiento inicial, que comprendía una parte descriptiva y una segunda parte histórica, mucho más breve que la primera ${ }^{12}$. Después, cuando estaba viviendo en el convento franciscano de Concepción en Chile (16o3-16o8), agregó nuevos apuntes, más rápidos que los anteriores, además de algunas notas que tenía guardadas, y describió, con sus observaciones del viaje anterior (1590-ca. 1597), a Tucumán y a Chile -que veía por segunda vez- y el Río de la Plata, adonde no había llegado aún ${ }^{13}$.

Lizárraga era hijo de uno de los conquistadores que llegaron a Quito en los primeros tiempos, y su libro nos evoca el ambiente inmediato a la conquista, cuando aún no se habían cicatrizado las heridas de las guerras civiles que concluyeron después de mediados del siglo. La única distinción que entre los españoles existía era la

${ }^{10}$ Descripción, II, LxvilI (pág. 642ab).

${ }^{11}$ Parece el párrafo final de esta primera redacción el siguiente: “Con lo hasta aquí tractado nos parece haber concluído con la brevedad posible, dejando escriptos los caminos desde Quito a Talina y lo demás digno de memoria subcedido en tiempo de los Virreyes que han gobernado los reinos del Perú, desde el marqués de Cañete don Hurtado de Mendoza, de buena memoria, hasta don García de Mendoza su hijo, subcesor en el marquesado; todo lo cual, a lo menos la mayor parte, habemos visto o sabido por relaciones verdaderas, que es lo menos que en estos ringlones dejamos a esta escritura encomendado, por que no quedase anegado en el profundo del río del olvido" (pág. 634 b).

${ }^{12}$ Quedan algunas huellas de esa doble redacción. Por ejemplo, en el cap. Lxi del libro II, que probablemente era el último de la primera redacción, dice Lizárraga del visitador Alonso Fernández de Bonilla (que murió en Lima el 2 de enero de 1600): "Ha hecho y hace su oficio con tanta rectitud y cristiandad cuanta se esperaba..., y aunque a algunos les parece va muy despacio y desean verle fuera destos reynos..."; y luego en el párrafo siguiente: "Como los hombres seamos mortales.... fué Nuestro Señor servido llevársele para sí de una enfermedad que casi no fué conocida de los médicos" (pág. 634ab).

${ }^{13}$ Descripción, I, c (pág. 555). 
de la fecha de llegada a las Indias: por eso distingue muy cuidadosamente, como el Inca Garcilaso, los "conquistadores viejos" o "los antiguos" - la primera nobleza indiana- de los "pobladores, venidos después de llana la tierra"14, y que les arrebataron la recompensa. Esa injusticia lo saca de su imperturbable objetividad, y recuerda con gratitud las palabras del licenciado Lope García de Castro al virrey Toledo, recién llegado al Perú, en favor de los antiguos, que comenta así:

Palabras verdaderas que procedieron de un ánimo cristiano benignísimo, muy prudente y gran servidor de Su Majestad, pues conocía las mercedes que Su Majestad, para descargo de su conciencia, debía hacer a los descendientes de los conquistadores; pero es la desventura de los conquistadores, pobladores y de los que de muchos años en estas partes vivimos (o por mejor decir, son nuestros pecados y de nuestros padres) que no hay quien venga de España, en la cual no se saben tener en una burrica ni limpiar las narices, ni en su vida echado mano a la espada (helos visto, en todo género de estado) que no les paresca los que vivimos en estos reinos de antiguo que somos poco menos que indios, y merecen ellos más en venir que los miserables conquistadores, pobladores ni sus hijos e nietos, ni los que ayudan a sustentar este reino y lo han ayudado a sustentar de cincuenta años a esta parte ${ }^{15}$.

La riqueza que los primeros lograron, Lizárraga había alcanzado a verla en su juventud; cuando escribía su libro, en cambio, se había cumplido aquella visión profética de Pedro Valdivia, que abandonó cierta vez grave y entristecido el corro alegre de sus amigos porque, según dijo, acababan de presentársele en la imaginación, allá en la corte, "los niños en las cunas y otros que se andan paseando o pasearán por ella muy pintados con medias de aguja y zapatos acuchillados, que han de venir a gozar de nuestros trabajos, y nuestros hijos e nietos han de morir de hambre"16. Aquella visión primera del Perú en tiempos del primer marqués de Cañete, la veía fray Reginaldo como una edad de oro muchos años después, y la evocaba nostálgicamente:

La primera vez que la vi [a la ciudad de Trujillo] era muy abundante y muy rica; los vecinos conquistadores unos hombrazos tan llenos de caridad para con los pasajeros, que en viendo en la plaza un hombre no conocido o nuevo en la tierra (que llamamos chapetón), a mía sobre tuya lo llevaban a su casa, lo hospedaban, regalaban y ayudaban para el camino si allá no

${ }^{14}$ Descripción, I, cxiIr (pág. $5^{6} 5$ ).

"5escripción, II, xxviI (págs. 599b-60oa).

${ }^{16}$ Ibid. 
le daba gusto hacer asiento; un vecino de aquellos cuando salía de su casa ocupaba toda la calle; no había mesón entonces, ni en muchos años después, ni carnicería; a todos sobraba lo necesario y aun más, y el que no lo tenía, no le faltaba, porque los encomenderos les enviaban el carnero, vaca y lo demás cada día. Liberalísimos para con los pobres; sus casas muy hartas, y sus cajas muy llenas de oro y plata ${ }^{17}$.

¿Cómo se perdió todo aquello, a juicio de fray Reginaldo? "Los vecinos viejos [de Arequipa] eran ricos; sus hijos son pobres porque no siguen la prudencia de sus padres, y los nietos de los conquistadores y vecinos serán paupérrimos"18. Los vecinos antiguos fueron todos ricos; "sus hijos, ahora, tienen abundancia de deudas y no les alcanza la sal al agua; gastan sin orden y sin discreción”. Y a pesar de la reserva que usa siempre, advertimos que considera las innovaciones introducidas por el virrey Toledo $\left(1569^{-1} 5^{81}\right)$ como el punto de partida de una nueva época, que en nada se parece a la anterior.

Habla como español, despectivamente, de los criollos, cuya educación confiada a indias o negras bebedoras, sucias y mentirosas, juzga detestable, aunque estima que son valientes; los mestizos, o montañeses, como los llaman en el Perú, le parecen peores aún: ladrones, rebeldes, y siempre mezclados con los indígenas, a quienes considera enemigos. Fray Reginaldo deja a otros la discusión de los problemas teóricos de la servidumbre del indio, que tan brillantemente habían resuelto los teólogos de su orden dominicana. Por su ministerio defiende a los indígenas aunque señala sus defectos: los considera serviles, cobardes, crueles, ingratos, mentirosos, bebedores, pleitistas, ladrones y perezosos. No parece muy seguro de la eficacia del remedio que propone para quitarles los defectos que no tenían antes de la Conquista -el robo, la mentira, la borrachera, el adulterio-, y que sería volver a usar con ellos el rigor de sus soberanos antiguos.

Lizárraga conoció un mundo abigarrado donde sobrevivía lo indígena, vivo pero fragmentado: a su pluma acudían naturalmente los vocablos que los españoles aprendieron en América y los empleaba a menudo sin explicarlos, por demasiado sabidos (icho, camote, jagüeyes, sabana, hamaca), o los traducía mentalmente a su lengua: usaba por ejemplo arriba y abajo, es decir Hañan y Urin, como equivalentes de sur y norte; alcanzó a asistir a las fiestas rituales; recorrió el camino del Inca, vió todavía sus defensas, semidestruídas lo mismo que sus desaguies, y sus tambos desiertos. Por todo ello, refleja fray Reginaldo un momento histórico preciso, aquel en que los europeos, de vuelta ya de las grandes ilusiones primeras, empiezan a ver la realidad tal cual es. Después de mụchas búsquedas, habían abandonado la espe-

17 Descripción, I, xvi (pág. 494b).

"Descripción, I, Lxvi (pág. $5^{23} b$ ). 
ranza de dar con la gran huaca o el tesoro que los enriquecería; la conquista, siempre vencedora, chocaba entonces con núcleos de indígenas irreductibles, feroces y astutos como los chiriguanos, o indomables como los araucanos.

Pero, a pesar de todo, subsistía y hasta se acrecentaba la leyenda, y con ella se consolaban de la realidad hostil los numerosos soldados -que eran los españoles solteros sin casa conocida-, que soñaban todavía con llegar a vecinos o encomenderos ricos. Lizárraga nos ayuda a comprenderlos, y a justificarlos.

En el "derrotero" de nuestro dominico van entretejidas breves anécdotas de conquistadores, recuerdos de la penuria pasada-como aquella marcha de Río Bamba a Quito por las tierras altas, con un frío tal que había que matar los caballos y meterse dentro para guare. cerse del frío ${ }^{19}$-; o leyendas de las guerras civiles - como aquella de los arenales de Villacuri, donde "es fama algunas noches oírse pífanos y atambores y grita de batalla, tropel de caballos con cascabeles, que pone no poca grima" y que evoca la derrota del capitán Lope Martín a manos del "tirano" Francisco Hernández Girón, favorito de criollos y españoles postergados ${ }^{20}$; cuentos de frailes oídos en las doctrinas - como la escena de las capullanas, que nos evoca una comunidad arcaica de tipo matriarcal ${ }^{21}$, o aquel otro de fray Domingo de Santo Tomás y el indio de Chincha ${ }^{22}$-; o los cuentos de caminantes - el de! soldado que invocó al diablo frente al río desbordado, y a quien el Señor pasó y repasó varias veces en castigo ${ }^{23}$-; algún milagro -el de Nuestra Señora de Copacabana con el indio que maltrataba a su esposa cristiana ${ }^{24}$-; las anécdotas de animales - la de las "tres mujeres enamoradas" y el caimán de Panamáa ${ }^{25}$, o la del perro picado por la víbora ${ }^{26}$.

Lizárraga es observador vivaz y penetrante, siempre curioso del

${ }^{10}$ Descripción, I, Lxix (pág. 526a).

- Descripción, I, Lx (pág. 521a).

${ }^{21}$ Descripción, I, vin (pág. 491a): "Estas capullanas, que eran las señoras, en su infidelidad se casaban las veces que querian, porque en no contentándolas el marido, le desechaban y casábanse con otro. El día de la boda, el marido escogido se sentaba junto a la señora y se hacia gran fiesta de borrachera; el desechado se hallaba alli, pero arrinconado, sentado en el suelo, llorando su desventura, sin que nadie le diese una sed de agua. Los novios, con gran alegría, haciendo burla del pobre".

${ }^{22}$ Descripción, I, LIX (pág. 620b): “A uno dellos preguntóle lo doctrina; no la supo o no quiso responder. Díjole el padre maestro: Pues cómo ¿no te enseñé yo la doctrina cristiana y la sabías muy bien? Respondió el indio: Padre, enseñándosela a mi hijo se me ha olvidado".

:2: Descripción, 1, xcill (pig. 545ab).

"+ Descripción, 1, Lxxxvi (págs. $\left.54^{1} b-54^{2} a\right)$.

${ }_{25}$ Descripción, I, v (págs. $488 b-489 a$ ).

${ }^{26}$ Descripción, I, LXXI (págs. $535^{b-536 a)}$. 
detalle concreto. No hay que buscar en su obra sino lo que él quiso poner en ella para que fuera una pequeña enciclopedia de saberes prácticos: uso de contrayerbas para víboras; consejos sobre los tiempos apropiados para las siembras; acerca de cómo se han de matar las hormigas; de los climas; de las lluvias; de las minas y técnica de laboreo. A esa enciclopedia manual le añadió una reseña histórica del período próximo, que aunque es tema marginal para el autor, ha crecido en importancia con el tiempo, y le ha otorgado un lugar distinguido entre los cronistas, por la exactitud y variedad de su información.

Bucnos Aires.

Julio Caillet - Bois 